\title{
Plasma oxylipin levels associated with preterm birth in preterm laboris
}

Maria Svenvik, Johanna Raffetseder, Lars Brudin, R. Lindberg, Marie Blomberg, Daniel Axelsson, Maria Jenmalm, Jan Ernerudh and M. L. Nording

The self-archived postprint version of this journal article is available at Linköping University Institutional Repository (DiVA):

http://urn.kb.se/resolve?urn=urn:nbn:se:liu:diva-174827

N.B.: When citing this work, cite the original publication.

Svenvik, M., Raffetseder, J., Brudin, L., Lindberg, R., Blomberg, M., Axelsson, D., Jenmalm, M., Ernerudh, J., Nording, M. L., (2021), Plasma oxylipin levels associated with preterm birth in preterm labor江, Prostaglandins, Leukotrienes and Essential Fatty Acids, 166, 102251.

https://doi.org/10.1016/j.plefa.2021.102251

Original publication available at:

https://doi.org/10.1016/j.plefa.2021.102251

Copyright: Elsevier

http://www.elsevier.com/

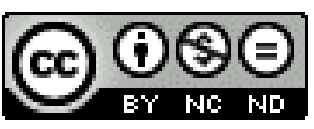




\section{Plasma oxylipin levels associated with preterm birth in preterm labor}

\section{Svenvik ${ }^{1,2}$, J. Raffetseder ${ }^{2}$, L. Brudin ${ }^{3,4}$, R. Lindberg ${ }^{5}$, M. Blomberg ${ }^{6}$, D. Axelsson ${ }^{2,7}$,}

M. C. Jenmalm², J. Ernerudh*8, and M. L. Nording*5

${ }^{1}$ Department of Obstetrics and Gynecology, Region Kalmar County, Kalmar, Sweden,

${ }^{2}$ Department of Biomedical and Clinical Sciences, Linköping University, Linköping, Sweden, ${ }^{3}$ Department of Clinical Physiology, Region Kalmar County, Kalmar, Sweden, ${ }^{4}$ Department of Health, Medicine and Caring Sciences, Linköping University, Linköping, Sweden, ${ }^{5}$ Department of Chemistry, Umeå University, Umeå, Sweden, ${ }^{6}$ Department of Obstetrics and Gynecology, and Department of Biomedical and Clinical Sciences, Linköping University, Linköping, Sweden, ${ }^{7}$ Department of Obstetrics and Gynecology, Ryhov County Hospital, Jönköping, Sweden, ${ }^{8}$ Department of Clinical Immunology and Transfusion Medicine, and Department of Biomedical and Clinical Sciences, Linköping University, Linköping, Sweden,

* J. Ernerudh and M. Nording contributed equally

\section{Corresponding author:}

Maria Svenvik

Department of Obstetrics and Gynecology

Kalmar County Hospital

S-391 85 Kalmar

Sweden

Telephone: +46722 193093

Fax number: Fax: +46 48084995

E-Mail: maria.svenvik@,regionkalmar.se

This work was supported by the Medical Research Council of Southeast Sweden (FORSS; grant number FORSS-931816; Region Kalmar County; and ALF grants, Region Östergötland, which were not involved in the work. 


\begin{abstract}
Introduction Preterm labor is a common clinical problem in obstetrics. Since the majority of women with preterm labor eventually deliver at full term, biomarkers are needed to more accurately predict who will deliver preterm. Oxylipins, given their importance in inflammation regulation, are highly interesting in this respect since labor is an inflammatory process.
\end{abstract}

Methods Eighty women with preterm labor before 34 weeks of gestation were enrolled in a prospective observational multi-center cohort study. Oxylipin levels of 67 analytes in plasma samples were analyzed by liquid chromatography coupled to tandem mass spectrometry.

Results Twenty-one (26\%) of the women delivered before 34 weeks of gestation, and of those women, fourteen delivered within 48 hours of admission. Logistic multivariate regression showed that lower levels of 9,10-DiHODE were associated with delivery before 34 weeks of gestation (aOR $0.12(0.024-0.62))$ and within 48 hours ((aOR $0.13(0.019-0.93)$ ).

Furthermore, higher levels of 11,12-DiHETrE were associated with delivery before 34 weeks of gestation ((aOR 6.19 (1.17-32.7)) and higher levels of 8-HETE were associated with delivery within 48 hours ((aOR 5.01 (1.13-22.14)).

Conclusions The oxylipin 9,10-DiHODE may be protective in preterm labor, both for delivery after 34 weeks of gestation and for delivery later than 48 hours of admission, whereas 11,12-DiHETrE and 8-HETE display the opposite effect. Larger studies are needed to validate these mediators as biomarkers for prediction of preterm birth following preterm labor.

\title{
KEYWORDS
}

Preterm labor, preterm birth, oxylipins, eicosanoids, biomarker, prediction 


\section{SUMMARY}

Labor is an inflammatory process. Oxylipins, which are important regulators of inflammation, are therefore highly relevant to explore as biomarkers in preterm labor in order to distinguish women with subsequent preterm birth from the majority of women with subsequent birth at full term, thereby avoiding unnecessary treatments. Plasma levels of 67 oxylipins were measured by liquid chromatography coupled to tandem mass spectrometry in 80 women with preterm labor before 34 weeks of gestation. Logistic multivariate regression showed that 9,10-DiHODE was protective both for delivery before 34 weeks of gestation and for delivery within 48 hours, whereas 11,12-DiHETrE had the opposite effect in relation to delivery before 34 weeks, and 8-HETE for delivery within 48 hours. Larger studies are needed to evaluate these compounds as potential predictive biomarkers for preterm birth following preterm labor. 


\section{INTRODUCTION}

Preterm labor is a clinical condition with regular uterine contractions and cervical ripening before 37 weeks of gestation, which potentially leads to preterm birth (PTB). PTB, defined as birth before 37 weeks of gestation, affects $11 \%$ of infants globally and is the leading cause of neonatal morbidity and mortality, and also the leading cause of death in children under the age of five [1-3]. However, a substantial proportion of women with preterm labor deliver at full term $[4,5]$. From a clinical point of view, preterm labor therefore constitutes a major problem, since it is crucial to correctly identify and treat women with imminent PTB, but also to avoid hospital admissions, hazardous transports to tertiary centers, and potentially injurious treatments for women who will eventually deliver at term. Although a short cervical length, as measured by transvaginal ultrasound, is associated with increased risk of PTB [6], more accurate prediction models are needed to improve clinical decision-making. In order to develop potential biomarkers, a better understanding of the underlying mechanisms is needed.

In this context, the changes in the immune system and its regulatory role during pregnancy are of great importance. Generally, pregnancy is associated with a shift toward immune tolerance [7] in order to avoid rejection of the semi-foreign fetus. This immune tolerance is broken at term and replaced by an inflammatory state that contributes to the initiation of labor. It is assumed that a lack, or preterm break, of tolerance is a basis for the inflammation that is involved in various pregnancy complications, including spontaneous PTB [8]. Due to the pivotal regulatory role of oxylipins in inflammation, these compounds might be relevant in immune regulation of pregnancy and highly relevant to explore as biomarkers in preterm labor.

Oxylipins are fatty acid metabolites that are important for a broad variety of conditions with an inflammatory component. They are derived from polyunsaturated fatty acids such as arachidonic acid (AA), linoleic acid (LA), eicosapentaenoic acid (EPA), docosahexaenoic acid (DHA), dihomo- $\gamma$-linolenic acid (DGLA), and $\alpha$-linolenic acid (ALA). The most important enzymatic cascades involved in the formation of oxylipins are catalyzed by cyclooxygenase (COX), lipoxygenase (LOX), and cytochrome P450 (CYP) [9]. AA-derived oxylipins are also known as eicosanoids. The most well-known group of oxylipins in relation to labor and pregnancy are found among the eicosanoids, namely the prostanoids, including prostaglandins, derived from AA by COX. Prostanoids are elevated in amniotic fluid before the onset of labor, both preterm and at term [10-12]. Furthermore, prostanoids and other oxylipins have been associated with gestational age at birth [13], and they are involved in 
multiple physiological processes of importance in pregnancy, for instance immune activation $[14,15]$, endothelial cell activation [16], resolution of inflammation $[17,18]$, and coagulation [19].

DHA supplementation in pregnancy and the impact on oxylipins and precursor fatty acids have been studied in the context of PTB, and it has been suggested that a subset of oxylipins might serve as potential early biomarkers for spontaneous PTB [20]. Furthermore, it has been proposed that low circulating levels of omega-3 polyunsaturated fatty acids are a risk factor for early PTB [21]. However, these findings do not reflect the specific situation of a woman presenting with symptoms of preterm labor, and it is not known how oxylipins are involved in the underlying mechanism of preterm labor, nor if oxylipin signatures might have the potential to predict PTB in women with preterm labor.

We therefore performed an exploratory study in women with preterm labor to investigate the signature of oxylipins in association with delivery before and after 34 weeks of gestation, and within and after 48 hours of hospital admission. The chosen time points ( 34 weeks and 48 hours, respectively) were based on clinical importance [22].

\section{MATERIALS AND METHODS}

\subsection{Study design and collection of samples}

A prospective observational multi-center cohort study was performed during 2014-2017 as previously described in a study of inflammatory proteins [5]. From that study, a sub-cohort of 80 women with preterm labor was included in the current study. Preterm labor was defined as regular painful uterine contractions before 34 weeks of gestation with cervical shortening (cervix $<25 \mathrm{~mm}$ ), measured by transvaginal ultrasound, or a cervical dilatation of more than one $\mathrm{cm}$, assessed by digital examination. All 80 women had intact membranes and were clinically assessed as having a high risk of delivery before 34 weeks of gestation. Accordingly, they were hospitalized and treated for preterm labor. The women were recruited from three different hospitals in the south-east region of Sweden. Two of the hospitals were secondary level centers (Jönköping and Kalmar) and one was a tertiary center (Linköping). All women had singleton pregnancies. Gestational age was determined by a standardized routine transabdominal ultrasound performed in the second trimester (week 12-19). Blood samples (EDTA tubes) were drawn immediately after admission to hospital, before initiation of any medical treatment. After being left for one-two hours at room temperature the 
tubes were centrifuged at $2500 \mathrm{~g}$ for ten minutes and the plasma was immediately frozen in aliquots at $-70^{\circ} \mathrm{C}$. In the two secondary level centers $(n=39$ and $n=26)$ pneumatic tube transport of the EDTA tubes was used, which was not the case in the tertiary center $(n=15)$.

\section{$\underline{\text { 2.2. Ethical approval }}$}

The study was approved by the Regional Ethical Review Board in Linköping, Sweden (2013/417-31 and 2016/421-32), and all women gave written informed consent to participate. The work was carried out according to the principles of the declaration of Helsinki.

\subsection{Analysis of oxylipins by a liquid chromatography tandem mass spectrometry method}

Unesterified oxylipins were isolated from plasma with solid phase extraction using Waters Oasis HLB cartridges (60 mg of sorbent, $30 \mu \mathrm{m}$ particle size), and then 67 individual analytes (Figure 1) were probed for by liquid chromatography (LC) coupled to tandem mass spectrometry (MS/MS) according to previously published protocols [23] with an additional set of ALA-derived epoxides and diols synthesized in-house. Separation of the analytes was performed using an Agilent Infinity 1290 (Agilent Technologies, CA, USA) LC equipped with a Waters BEH C18 column $(2.1 \mathrm{~mm} \times 150 \mathrm{~mm}, 130 \AA, 1.7 \mu \mathrm{m}$ particle size $)$ using a gradient of water (0.1\% acetic acid) and acetonitrile:isopropanol (90:10) as mobile phases. An Agilent 6495 triple quadrupole mass spectrometer was used in negative electrospray ionization mode for dynamic multiple reaction monitoring of fragment ions (two for each analyte, one for quantification and one for qualification purposes). Chromatograms were evaluated manually using an in-house script and quantification of oxylipins was performed using external calibration curves as described previously [24]. The abbreviations of each oxylipin are explained in supplementary table $\mathrm{S} 1$.

\subsection{Data analyses}

For comparison of clinical characteristics, non-parametric analyses were made for continuous variables (Mann-Whitney $U$-test) and a Chi-2 test or Fisher's exact test were used when appropriate for categorical variables. P-values $<0.05$ were considered significant.

The Mann-Whitney $U$-test, or Chi-2 test when appropriate, was used for screening of differences in oxylipin concentrations between groups and also for investigations of systematic differences between hospitals. 
Oxylipins with a difference in concentrations between groups at a p-value $<0.1$ were further analyzed with logistic quantile regression in univariate and multivariate models. Here, only oxylipins with at least $40 \%$ of values above the limit of detection (LOD) were taken into consideration, and values below LOD were substituted with $\mathrm{LOD} / \sqrt{2}$ [25]. Multivariate logistic quantile regression models were adjusted for usage of pneumatic tube systems for sample transport, as this may affect oxylipin levels [26]. Adjacent quartiles of statistically significant variables were combined if the actual frequencies were similar or opposite to the significant trend.

The software Statistica v.13.5.0.17 (TIBCO Software Inc., Palo Alto, CA, USA) and GraphPad Prism v. 8.3.0 for Windows (GraphPad Software, San Diego, CA, USA) were used for all analyses.

\section{RESULTS}

Of the 80 women included in the study, 21 (26\%) delivered before 34 weeks of gestation. Of those, 14 women delivered within 48 hours after admission to hospital. Hence, 59 women (74\%) delivered after 34 weeks, whereas 66 (82\%) women delivered later than 48 hours after admission (Figure 2).

Clinical characteristics have been reported previously, in the context of inflammatory proteins [5]. Briefly, women who delivered $<34$ weeks $(n=21)$ had higher BMI (median 25 (range 2046) versus $22(16-41), p=0.011)$, a higher proportion of nulliparity ( $81 \%$ versus $27 \%$, $\mathrm{p}=0.010)$, and shorter cervical length (7 mm (0-49) versus $16 \mathrm{~mm}(4-40), \mathrm{p}<0.001)$ compared to women who delivered $\geq 34$ weeks (Table 1 ). The women with delivery within 48 hours after admission had a higher BMI (25 (20-46) versus $22(16-41), \mathrm{p}=0.022)$ and a shorter cervical length $(9(0-40)$ versus $16(0-40), p=0.008)$ than the women with delivery after 48 hours (Table 1). Regarding age, tobacco use, and gestational age at inclusion, there were no significant differences between either of the groups.

According to the initial non-stringent $(\mathrm{p}<0.1)$ screening, using a Mann-Whitney $U$-test (supplementary Table S2), women with delivery before 34 weeks of gestation had lower concentrations of 9-HOTrE ( $p=0.09), 9,10-\operatorname{DiHOME}(\mathrm{p}=0.09)$, and 9,10-DiHODE $(p=0.02)$ and higher concentrations of 8 -HETE $(\mathrm{p}=0.02)$ and 11,12-DiHETrE $(\mathrm{p}=0.08)$ compared to women with delivery after 34 weeks (Figure 3). Furthermore, women with delivery within 48 
hours after inclusion displayed higher concentrations of 8-HETE $(p=0.05)$ and lower concentrations of 9,12,13-TriHOME $(\mathrm{p}=0.06), 9,10$-DiHOME $(\mathrm{p}=0.08)$, and 9,10-DiHODE $(p=0.02)$ compared to women with delivery after 48 hours (Figure 4$)$. The association between these oxylipins and time of delivery was further analyzed with univariate and multivariate logistic regression.

In the univariate logistic regression analysis, there was an association with delivery before 34 weeks of gestation and lower concentrations of 9,10-DiHOME, 9,10-DiHODE, and 9-HOTrE, as well as an association with higher concentrations of 8-HETE and 11,12-DiHETrE (Table 2). In the multivariate analysis, two oxylipins remained significantly associated with delivery before 34 weeks of gestation. Forty percent of women with concentrations of 9,10-DiHODE in the lowest two quartiles $(<0.237 \mathrm{pmol} / \mathrm{mL})$ delivered before 34 weeks compared to $10 \%$ of women with concentrations in the highest quartile $(>0.441 \mathrm{pmol} / \mathrm{mL})$ (adjusted OR 0.12 (0.024-0.62); $\mathrm{p}=0.012$ ) (Table 2). The multivariate analysis also showed a significant association between delivery before 34 weeks and higher concentrations of 11,12-DiHETrE; $15 \%$ of women with concentrations in the lowest quartile $(\leq 0.486 \mathrm{pmol} / \mathrm{mL})$ gave birth before 34 weeks compared to $45 \%$ of women with concentrations of 11,12-DiHETrE in the highest quartile ( $>0.739)$ (adjusted OR 6.19 (1.17-32.7); $\mathrm{p}=0.032$ ) (Table 2). Data for all quartiles is shown in Supplementary Tables S3 and S4.

Regarding delivery within 48 hours of hospital admission, there was a univariate association with lower concentrations of 9,10-DiHOME, and 9,10-DiHODE as well as an association with higher concentrations of 8-HETE (Table 3). After multivariate analysis, the two remaining oxylipins with a significant association with delivery within 48 hours were 9,10DiHODE and 8-HETE. Concerning 9,10-DiHODE, 28\% of women with concentrations in the two lowest quartiles $(<0.237 \mathrm{pmol} / \mathrm{mL})$ of this oxylipin delivered within 48 hours compared to $5 \%$ of women with concentrations in the highest quartile $(>0.441 \mathrm{pmol} / \mathrm{mL})$ (adjusted OR $0.13(0.019-0.93) ; \mathrm{p}=0.042)$. The corresponding numbers for 8 -HETE were $7 \%$ delivery within 48 hours in the two lowest quartiles and $28 \%$ in the two highest quartiles (adjusted OR 5.01 (1.13-22.14); $\mathrm{p}=0.034)$ (Table 3).

Furthermore, since the sampling protocol and pneumatic tube transport have been reported to influence a subset of oxylipins [26], we investigated the potential impact of these factors on our data set. In the univariate logistic regression analysis there was a tendency to find a statistically significant association between not using pneumatic tube transport and delivery before 34 weeks ( $\mathrm{p}=0.053$ ); however, in the multivariate analysis an association was not 
verified ( $\mathrm{p}=0.127$ ) (Table 2 ). Regarding delivery within 48 hours, the use of pneumatic tube transport had no impact on the results (Table 3).

There was a numerically higher proportion of women with delivery before 34 weeks $(47 \%)$ and within 48 hours $(27 \%)$ at the tertiary center compared to the two secondary centers $(21 \%$ and $23 \%$, respectively, for delivery before 34 weeks, and $13 \%$ and $19 \%$, respectively, for delivery within 48 hours). However, this was not a significant difference $(\mathrm{p}>0.05)$. There were no significant differences regarding frequencies of detected analytes when comparing hospitals (data not shown).

\section{DISCUSSION AND CONCLUSIONS}

In this prospective multi-center observational cohort study, we report, for the first time that there are a few, but important, oxylipins that are significantly associated with PTB in women presenting with preterm labor. In particular, 9,10-DiHODE and 11,12-DiHETrE were independently associated with PTB before or after 34 weeks of gestation. Both compounds are dihydroxy fatty acids derived via the CYP pathway, although 9,10-DiHODE is derived from ALA while 11,12-DiHETrE is derived from AA. Interestingly, 9,10-DiHODE and 11,12-DiHETrE showed opposing effects; 9,10-DiHODE being protective and 11,12DiHETrE being harmful in relation to PTB. For delivery within 48 hours of hospital admission, again 9,10-DiHODE showed a protective effect, and here 8-HETE was associated with an increased risk of impending PTB. Although oxylipins are mechanistically relevant to the pro-inflammatory state of PTB, and the findings support a role of selected oxylipins as biomarkers, further studies are needed to establish their clinical utility.

In the present study, we chose 34 weeks of gestation as a cut-off for clinically relevant PTB. In guidelines [22] it is recommended that corticosteroids are given to pregnant women with preterm labor and a high risk of delivery before 34 weeks of gestation in order to decrease respiratory distress complications in the neonate. It is also generally considered that the full effect of corticosteroids is achieved after 48 hours. Therefore, the gestational age of 34 weeks and the time interval of 48 hours after admission are very important in the clinical setting.

High levels of 9,10-DiHODE were associated with delivery after gestational week 34 and later than 48 hours of admission to the hospital, which implies a protective effect of 9,10DiHODE in relation to spontaneous PTB. 9,10-DiHODE is an ALA-derived dihydroxy fatty 
acid produced via the CYP pathway. It has been associated with pregnancy in analyses of bovine corpora lutea [27]. Furthermore, CYP products (together with LOX products) have been recognized as the most prominent among the oxylipins for identifying overall and spontaneous preterm birth [28], although 9,10-DiHODE was not included in that study. DiHODEs such as 9,10-DiHODE are not commercially available, which in part may have hampered investigations of their role in PTB. Our findings underline the need for a comprehensive panel of analytes in studies of preterm labor and PTB, including ALA-derived oxylipins such as DiHODEs.

High levels of another dihydroxy fatty acid, namely 11,12-DiHETrE (also known as 11,12DHET), derived from AA via the CYP pathway, were associated with delivery before gestational week 34, which implies a harmful effect of 11,12-DiHETrE in terms of spontaneous PTB. Earlier studies of 11,12-DiHETrE have shown that it is significantly associated with increased odds of preterm birth, as stated in the review article by Aung et al. [28]; however, this was in asymptomatic women, hence not in the setting of preterm labor. The opposite association of the omega-6 AA-derived 11,12-DiHETrE compared to the omega-3 ALA-derived 9,10-DiHODE with PTB emphasizes the complexity of oxylipin pathways in which the same enzymes catalyze the conversion of a range of fatty acid parent compounds, some with anti-inflammatory properties, and others with pro-inflammatory properties. The finding of opposing effects is intriguing since in a protein screening [5] of 92 proteins, none was found to be protective in relation to PTB. Thus, it is relevant to consider mechanisms for protective effects with emphasis on the anti-inflammatory and pro-resolving effects of oxylipins. Interestingly, omega-3 supplementation has been associated with decreased risk of PTB [28, 29], and low plasma concentration of omega-3 EPA and DHA is a distinct risk factor for PTB [21]. In a recent study, Simmonds et al.[30] reported that women with singleton pregnancies and low total omega-3 PUFA status early in pregnancy had an increased risk of preterm birth before 34 weeks of gestation, and that omega-3 supplementation (DHA and EPA) could reduce that risk. Although the study population in Simmonds's work were asymptomatic women in early pregnancy, which are not clinically comparable to our study population of women with symptoms of PTL, it demonstrates the importance of PUFA status in relation to preterm birth, not only the potential effect of individual oxylipins. Ramsden et al.[20] investigated whether the protective effect of oxylipins was mediated by increasing levels of DHA-derived oxylipins, while reducing AAderived oxylipins, such as prostaglandins and other prostanoids, which are implicated in 
uterine contractility, or by modulation of immune activation, such as HETEs [20]. Unfortunately, they were not able to detect any prostanoids since the levels were below the limit of quantitation in all plasma samples. Levels of prostanoids were below the LOD also in our study, so it was not possible to investigate the effect of prostaglandins on PTB in preterm labor in the current study either. Other potential limitations include keeping blood samples at room temperature for an extended period of time prior to centrifugation, so potential ex-vivo formation and degradation processes cannot be excluded and thus data on platelet derived oxylipin such as $\mathrm{TXB}_{2}$ as well as 12-HETE need to be interpreted with caution [26]. Furthermore, pneumatic tube transport was used for sample delivery at two of the three hospitals in this study, a procedure with a potential impact on oxylipin content [26]. Although pneumatic tube transport did not significantly affect oxylipin levels, the use of pneumatic tube transport was adjusted for in the statistical analyses as an extra precaution.

Beyond the dihydroxy fatty acids, high levels of the 8-HETE were associated with delivery within 48 hours of admission to hospital. 8-HETE is a monohydroxy fatty acid derived from non-enzymatic oxidation of AA, or via the LOX pathway. 8-HETE was not associated with PTB in Aung et al. [28]. Moreover, in the univariate analysis, there was an association between higher levels of 8-HETE and delivery before 34 weeks. Other findings in the univariate analysis only were that 9-HOTrE seemed to have a protective effect regarding delivery before 34 weeks, as did 9,10-DiHOME, which was protective in relation to both delivery before 34 weeks and within 48 hours. In Aung et al. [28], 9,10-DiHOME was also a significant finding, but with an opposite effect, as it was associated with increased risk of spontaneous PTB. Comparison between the studies must be made with caution, as the study of Aung et al. was performed on asymptomatic women and not women with preterm labor, where inflammatory cascades are supposedly augmented. Interpretation of the results in the univariate regression model should be carried out cautiously as it is possible that one of the oxylipins is dependent on another oxylipin to exert its effect on the outcome. Furthermore, it is possible that clearance of investigated PUFA metabolites, at least in part, contributes to our results, in line with findings on glucuronidation of AA and LA metabolites [31]. Urine analysis needs to be included in future studies in order to investigate the significance of glucuronidation.

In conclusion, in this study of women with preterm labor before 34 weeks of gestation, 9,10DiHODE and 11,12-DiHETrE were both associated with delivery before 34 weeks, but in opposite directions. 9,10-DiHODE was additionally associated with delivery later than 48 
hours after hospital admission, whereas 8-HETE was associated with delivery within 48 hours. To our knowledge, there are no previous findings reporting on the association between preterm labor and these three oxylipins, implying that this is a novel and interesting finding, although it needs to be verified in larger studies whether 9,10-DiHODE, 11,12-DiHETrE, and 8-HETE can serve as biomarkers for PTB in preterm labor.

\section{ACKNOWLEDGMENTS}

The Swedish Metabolomics Centre (www.swedishmetabolomicscentre.se) is acknowledged for access to instrumentation.

\section{REFERENCES}

[1] H. Blencowe, S. Cousens, D. Chou, et al., Born too soon: the global epidemiology of 15 million preterm births, Reprod Health, 10 Suppl 1 (2013) S2.

[2] J.P. Vogel, S. Chawanpaiboon, A.B. Moller, K. Watananirun, M. Bonet, P. Lumbiganon, The global epidemiology of preterm birth, Best Pract Res Clin Obstet Gynaecol, 52 (2018) 3-12.

[3] S. Chawanpaiboon, J.P. Vogel, A.B. Moller, et al., Global, regional, and national estimates of levels of preterm birth in 2014: a systematic review and modelling analysis, Lancet Glob Health, 7 (2019) e37-e46.

[4] R.L. Goldenberg, J.F. Culhane, J.D. Iams, R. Romero, Epidemiology and causes of preterm birth, Lancet, 371 (2008) 75-84.

[5] M. Svenvik, M.C. Jenmalm, L. Brudin, et al., High-sensitivity detection of inflammation-associated plasma proteins predicts preterm birth in preterm labor, Manuscript.

[6] V. Berghella, M. Palacio, A. Ness, Z. Alfirevic, K.H. Nicolaides, G. Saccone, Cervical length screening for prevention of preterm birth in singleton pregnancy with threatened preterm labor: systematic review and meta-analysis of randomized controlled trials using individual patient-level data, Ultrasound in obstetrics \& gynecology : the official journal of the International Society of Ultrasound in Obstetrics and Gynecology, 49 (2017) 322-329.

[7] J. Svensson-Arvelund, J. Ernerudh, E. Buse, et al., The Placenta in Toxicology. Part II: Systemic and Local Immune Adaptations in Pregnancy, Toxicologic pathology, 42 (2014) 327-338.

[8] N. Gomez-Lopez, D. StLouis, M.A. Lehr, E.N. Sanchez-Rodriguez, M. Arenas-Hernandez, Immune cells in term and preterm labor, Cell Mol Immunol, 11 (2014) 571-581.

[9] E.A. Dennis, P.C. Norris, Eicosanoid storm in infection and inflammation, Nature reviews. Immunology, 15 (2015) 511-523.

[10] J.Y. Park, R. Romero, J. Lee, P. Chaemsaithong, N. Chaiyasit, B.H. Yoon, An elevated amniotic fluid prostaglandin F2alpha concentration is associated with intra-amniotic inflammation/infection, and clinical and histologic chorioamnionitis, as well as impending preterm delivery in patients with preterm labor and intact membranes, The journal of maternal-fetal \& neonatal medicine : the official journal of the European Association of Perinatal Medicine, the Federation of Asia and Oceania Perinatal Societies, the International Society of Perinatal Obstet, 29 (2016) 2563-2572.

[11] S.E. Lee, I.S. Park, R. Romero, B.H. Yoon, Amniotic fluid prostaglandin F2 increases even in sterile amniotic fluid and is an independent predictor of impending delivery in preterm premature rupture of membranes, The journal of maternal-fetal \& neonatal medicine : the official journal of the European Association of Perinatal Medicine, the Federation of Asia and Oceania Perinatal Societies, the International Society of Perinatal Obstet, 22 (2009) 880-886. 
[12] S.E. Lee, R. Romero, I.S. Park, H.S. Seong, C.W. Park, B.H. Yoon, Amniotic fluid prostaglandin concentrations increase before the onset of spontaneous labor at term, The journal of maternal-fetal \& neonatal medicine : the official journal of the European Association of Perinatal Medicine, the Federation of Asia and Oceania Perinatal Societies, the International Society of Perinatal Obstet, 21 (2008) 89-94.

[13] S. Gouveia-Figueira, D.S. Martens, T.S. Nawrot, M.L. Nording, Cord blood eicosanoid signatures and newborn gestational age, Prostaglandins Other Lipid Mediat, 133 (2017) 123-127.

[14] R. Romero, M. Emamian, M. Wan, R. Quintero, J.C. Hobbins, M.D. Mitchell, Prostaglandin concentrations in amniotic fluid of women with intra-amniotic infection and preterm labor, American journal of obstetrics and gynecology, 157 (1987) 1461-1467.

[15] R. Romero, R. Quintero, M. Emamian, et al., Arachidonate lipoxygenase metabolites in amniotic fluid of women with intra-amniotic infection and preterm labor, American journal of obstetrics and gynecology, 157 (1987) 1454-1460.

[16] G.C. Shearer, J.W. Newman, Impact of circulating esterified eicosanoids and other oxylipins on endothelial function, Current atherosclerosis reports, 11 (2009) 403-410.

[17] C.N. Serhan, Pro-resolving lipid mediators are leads for resolution physiology, Nature, 510 (2014) 92-101.

[18] T.M. Nordgren, A. Anderson Berry, M. Van Ormer, et al., Omega-3 Fatty Acid Supplementation, Pro-Resolving Mediators, and Clinical Outcomes in Maternal-Infant Pairs, Nutrients, 11 (2019).

[19] R. Adili, M. Hawley, M. Holinstat, Regulation of platelet function and thrombosis by omega-3 and omega-6 polyunsaturated fatty acids, Prostaglandins Other Lipid Mediat, 139 (2018) 10-18.

[20] C.E. Ramsden, M. Makrides, Z.X. Yuan, et al., Plasma oxylipins and unesterified precursor fatty acids are altered by DHA supplementation in pregnancy: Can they help predict risk of preterm birth?, Prostaglandins, leukotrienes, and essential fatty acids, 153 (2020) 102041.

[21] S.F. Olsen, T.I. Halldorsson, A.L. Thorne-Lyman, et al., Plasma Concentrations of Long Chain N-3 Fatty Acids in Early and Mid-Pregnancy and Risk of Early Preterm Birth, EBioMedicine, 35 (2018) 325333.

[22] D. Roberts, J. Brown, N. Medley, S.R. Dalziel, Antenatal corticosteroids for accelerating fetal lung maturation for women at risk of preterm birth, Cochrane Database Syst Rev, 3 (2017) CD004454.

[23] J. Spath, T. Brodin, D. Cerveny, R. Lindberg, J. Fick, M.L. Nording, Oxylipins at intermediate larval stages of damselfly Coenagrion hastulatum as biochemical biomarkers for anthropogenic pollution, Environ Sci Pollut Res Int, (2021).

[24] S. Gouveia-Figueira, M.L. Nording, Validation of a tandem mass spectrometry method using combined extraction of 37 oxylipins and 14 endocannabinoid-related compounds including prostamides from biological matrices, Prostaglandins Other Lipid Mediat, 121 (2015) 110-121.

[25] A. Vasudevan, A.G. Munkres, T. Bottiglieri, J.I. Won, P. Garg, P.A. McCullough, Computation of a cardiac severity score with left-censored biomarkers for patients with heart failure, Pathology and Laboratory Medicine International, 9 (2107) 15-20.

[26] K.M. Rund, F. Nolte, J. Doricic, et al., Clinical blood sampling for oxylipin analysis - effect of storage and pneumatic tube transport of blood on free and total oxylipin profile in human plasma and serum, Analyst, 145 (2020) 2378-2388.

[27] M.P.T. Owen, E.J. Northrop, J.J.J. Rich, et al., Oxylipin concentrations in bovine corpora lutea during maternal recognition of pregnancy, Theriogenology, 142 (2020) 384-389.

[28] M.T. Aung, Y. Yu, K.K. Ferguson, et al., Prediction and associations of preterm birth and its subtypes with eicosanoid enzymatic pathways and inflammatory markers, Sci Rep, 9 (2019) 17049.

[29] P. Middleton, J.C. Gomersall, J.F. Gould, E. Shepherd, S.F. Olsen, M. Makrides, Omega-3 fatty acid addition during pregnancy, Cochrane Database Syst Rev, 11 (2018) CD003402.

[30] L.A. Simmonds, T.R. Sullivan, M. Skubisz, et al., Omega-3 fatty acid supplementation in pregnancy-baseline omega-3 status and early preterm birth: exploratory analysis of a randomised controlled trial, BJOG : an international journal of obstetrics and gynaecology, 127 (2020) 975-981. [31] D. Turgeon, S. Chouinard, P. Belanger, et al., Glucuronidation of arachidonic and linoleic acid metabolites by human UDP-glucuronosyltransferases, J Lipid Res, 44 (2003) 1182-1191. 


\section{TABLES}

Table 1. Maternal characteristics of women with preterm labor presented separately for those who delivered at $<34$ and $\geq 34$ weeks of gestation, and those who delivered within 48 hours and later, respectively. Non-parametric analyses were conducted for continuous parameters (Mann-Whitney $U$-test) and Chi-2 test or Fisher's exact test when appropriate for categorical variables.

\begin{tabular}{|c|c|c|c|c|c|c|}
\hline & \multicolumn{3}{|c|}{ Time of delivery } & \multicolumn{3}{|c|}{ Time from inclusion to delivery } \\
\hline & $<34$ weeks & $\geq 34$ weeks & Diff & $\leq 48$ hours & $>48$ hours & Diff \\
\hline Variable & & & $\mathbf{p}$ & & & $\mathbf{p}$ \\
\hline $\mathbf{N}$ & 21 & 59 & & 14 & 66 & \\
\hline \multicolumn{7}{|l|}{ Age } \\
\hline Median (IQR) & $27(25-30)$ & $27(25-31)$ & 1.000 & $28(25-31)$ & $27(25-31)$ & 0.797 \\
\hline \multicolumn{7}{|l|}{$\begin{array}{l}\text { Body mass index } \\
\left(\mathrm{kg} / \mathrm{m}^{2}\right)\end{array}$} \\
\hline Median (IQR) & $25(22-32)$ & $22(20-26)$ & 0.011 & $25(22-30)$ & $22(20-26)$ & 0.022 \\
\hline \multicolumn{7}{|c|}{ Tobacco use during pregnancy $(\mathrm{n} ; \%)$} \\
\hline No & $17(85)$ & $41(71)$ & & $11(85)$ & $47(72)$ & \\
\hline Yes & $3(15)$ & $17(29)$ & 0.249 & $2(15)$ & $18(28)$ & 0.496 \\
\hline \multicolumn{7}{|c|}{ Parity at inclusion (n; \%) } \\
\hline Nulliparous & $17(81.0)$ & $27(45.8)$ & & $10(71.4)$ & $34(51.5)$ & \\
\hline Parous & $4(19.0)$ & $32(54.2)$ & 0.010 & $4(28.6)$ & $32(48.5)$ & 0.240 \\
\hline \multicolumn{7}{|c|}{ Gestational week at inclusion } \\
\hline Median (IQR) & $30(28-33)$ & $30(28-32)$ & 0.453 & $28(28-33)$ & $31(28-32)$ & 0.543 \\
\hline \multicolumn{7}{|l|}{ Cervical length (mm) } \\
\hline Median (IQR) & $7(0-12)$ & $16(12-20)$ & $<0.001$ & $9(0-13)$ & $16(12-20)$ & 0.008 \\
\hline \multicolumn{7}{|c|}{ Time from inclusion to delivery $(\mathrm{n} ; \%)$} \\
\hline $0-48 h$ & $14(66.7)$ & $0(0.0)$ & & $14(100.0)$ & $0(0.0)$ & \\
\hline 2-7 d & $6(28.6)$ & $2(3.4)$ & & $0(0.0)$ & $8(12.1)$ & \\
\hline$>7 d$ & $1(4.8)$ & $57(96.6)$ & $<0.001$ & $0(0.0)$ & $58(87.9)$ & - \\
\hline \multicolumn{7}{|l|}{ Time of delivery ( $\mathrm{n} ; \%)$} \\
\hline$<34$ weeks & - & - & & $14(100)$ & $7(11)$ & \\
\hline$\geq 34$ weeks & - & - & - & $0(0)$ & $59(89)$ & $<0.001$ \\
\hline
\end{tabular}

$\mathrm{IQR}=$ inter quartile range 
Table 2. Oxylipins ( $\mathrm{pmol} / \mathrm{mL})$ significantly associated with delivery before 34 weeks of gestation following preterm labor analyzed using logistic regression. In the multivariate model the variables were adjusted for pneumatic tube transport.

\begin{tabular}{|c|c|c|c|c|c|c|c|}
\hline \multirow[b]{2}{*}{ Variable } & \multirow[b]{2}{*}{ Total } & \multicolumn{2}{|c|}{$\begin{array}{c}\text { Delivery } \\
<\text { week } 34\end{array}$} & \multicolumn{2}{|c|}{$\begin{array}{l}\text { Univariate logistic } \\
\text { regression }\end{array}$} & \multicolumn{2}{|c|}{$\begin{array}{l}\text { Multivariate logistic } \\
\text { regression }\end{array}$} \\
\hline & & $\mathrm{n}$ & $\%$ & OR $(95 \% \mathrm{Cl})$ & $\mathbf{p}$ & OR $(95 \% \mathrm{Cl})$ & $\mathbf{p}$ \\
\hline \multicolumn{8}{|c|}{ Pneumatic tube transport } \\
\hline No & 15 & 7 & 47 & 1.00 & & 1.00 & \\
\hline Yes & 65 & 14 & 22 & $0.31(0.10-1.03)$ & 0.053 & $0.36(0.10-1.35)$ & 0.127 \\
\hline
\end{tabular}

\section{9,10-DiHOME Quartiles}

$\begin{array}{lccccc}<2.859(\mathrm{Q} 1+\mathrm{Q} 2)^{*} & 40 & 14 & 35 & 1.00 & \\ 2.859-4.872 & 20 & 5 & 25 & 0.49(0.24-1.00) & \\ >4.872 & 20 & 2 & 10 & 0.24(0.06-0.99) & 0.049\end{array}$

\section{9,10-DiHODE Quartiles}

\begin{tabular}{|c|c|c|c|c|c|c|c|}
\hline$<0.237(\mathrm{Q} 1+\mathrm{Q} 2)^{*}$ & 40 & 16 & 40 & 1.00 & & 1.00 & \\
\hline $0.237-0.441$ & 20 & 3 & 15 & $0.37(0.17-0.81)$ & & $0.35(0.16-0.79)$ & \\
\hline$>0.441$ & 20 & 2 & 10 & $0.14(0.03-0.66)$ & 0.014 & $0.12(0.024-0.62)$ & 0.012 \\
\hline
\end{tabular}

\section{9-HOTrE Quartiles}

$\begin{array}{lccccc}\leq 702(\mathrm{Q} 1+\mathrm{Q} 2)^{*} & 40 & 14 & 35 & 1.00 & \\ 0.703-1.521 & 20 & 5 & 25 & 0.49(0.24-1.00) & \\ >1.521 & 20 & 2 & 10 & 0.24(0.06-0.99) & 0.049\end{array}$

\section{8-HETE Quartiles}

$\begin{array}{lccccc}\leq 0.020(\mathrm{Q} 1+\mathrm{Q} 2)^{*} & 41 & 6 & 15 & 1.00 & \\ >0.020(\mathrm{Q} 3+\mathrm{Q} 4)^{*} & 39 & 15 & 38 & 3.65(1.22-10.92) & 0.021\end{array}$

\section{1,12-DiHETrE Quartiles}

\begin{tabular}{|c|c|c|c|c|c|c|c|}
\hline$\leq 0.486$ & 20 & 3 & 15 & 1.00 & & 1.00 & \\
\hline $0.487-0.739(\mathrm{Q} 2+\mathrm{Q} 3)^{*}$ & 40 & 9 & 23 & $2.26(1.04-4.90)$ & & $2.49(1.08-5.72)$ & \\
\hline$>0.739$ & 20 & 9 & 45 & $5.12(1.09-24.05)$ & 0.039 & $6.19(1.17-32.74)$ & 0.032 \\
\hline
\end{tabular}

*Adjacent quartiles of statistically significant variables are combined when the actual frequencies were similar or opposite to the significant trend (see corresponding supplementary tables S3). 
Table 3. Oxylipins ( $\mathrm{pmol} / \mathrm{mL}$ ) significantly associated with delivery within 48 hours after admission to hospital due to preterm labor analyzed using logistic regression.

\begin{tabular}{|c|c|c|c|c|c|c|c|}
\hline \multirow[b]{2}{*}{ Variable } & \multirow[b]{2}{*}{ Total } & \multicolumn{2}{|c|}{$\begin{array}{c}\text { Delivery < } \\
48 \text { hours }\end{array}$} & \multicolumn{2}{|c|}{$\begin{array}{l}\text { Univariate logistic } \\
\text { regression }\end{array}$} & \multicolumn{2}{|c|}{$\begin{array}{l}\text { Multivariate logistic } \\
\text { regression }\end{array}$} \\
\hline & & $\mathbf{n}$ & $\%$ & OR $(95 \% \mathrm{Cl})$ & $p$ & OR $(95 \% \mathrm{Cl})$ & p \\
\hline \multicolumn{8}{|c|}{ Pneumatic tube transport } \\
\hline No & 15 & 4 & 27 & 1.00 & & 1.00 & \\
\hline Yes & 65 & 10 & 15 & $0.50(0.13-1.93)$ & 0.306 & $1.05(0.23-4.82)$ & 0.954 \\
\hline
\end{tabular}

9,12,13-TriHOME Quartiles

$\begin{array}{lccccc}\leq 3.332(\mathrm{Q} 1+\mathrm{Q} 2+\mathrm{Q} 3)^{*} & 60 & 13 & 22 & 1.00 & \\ >3.332 & 20 & 1 & 5 & 0.19(0.02-1.61) & 0.126\end{array}$

9,10-DiHOME Quartiles

$\begin{array}{lccccc}\leq 1.701 & 20 & 6 & 30 & 1.00 & \\ 1.701-2.858 & 20 & 4 & 20 & 0.55(0.31-0.99) & \\ 2.859-4.872 & 20 & 3 & 15 & 0.30(0.09-0.98) & \\ >4.872 & 20 & 1 & 5 & 0.17(0.03-0.97) & 0.046\end{array}$

\section{9,10-DiHODE Quartiles}

\begin{tabular}{|c|c|c|c|c|c|c|c|}
\hline$<0.237(\mathrm{Q} 1+\mathrm{Q} 2)^{*}$ & 40 & 11 & 28 & 1.00 & & 1.00 & \\
\hline $0.237-0.441$ & 20 & 2 & 10 & $0.35(0.13-0.93)$ & & $0.36(0.14-0.97)$ & \\
\hline$>0.441$ & 20 & 1 & 5 & $0.12(0.017-0.87)$ & 0.036 & $0.13(0.019-0.93)$ & 0.042 \\
\hline
\end{tabular}

\section{8-HETE Quartiles}

\begin{tabular}{lccccccc}
$\leq 0.020(\mathrm{Q} 1+\mathrm{Q} 2)^{*}$ & 41 & 3 & 7 & 1.00 & & 1.00 \\
$>0.020(\mathrm{Q} 3+\mathrm{Q} 4)^{*}$ & 39 & 11 & 28 & $4.98(1.24-19.95)$ & 0.024 & $5.01(1.13-22.14)$ & 0.034 \\
\hline
\end{tabular}

*Adjacent quartiles of statistically significant variables are combined when the actual frequencies were similar or opposite to the significant trend (see corresponding supplementary tables S4). 


\section{FIGURE LEGENDS}

Figure 1. Overview of the oxylipins included in the analysis. Oxylipins marked in bold were significantly associated with delivery before 34 weeks of gestation and/or within 48 hours after inclusion in the study.

Figure 2. Flow chart (panels A and B) and inclusion chart (panel C) of women with threatened preterm labor (PTL). The bars in panel C represent gestational age at inclusion and at delivery for individual women. The red bars represent those who delivered before 34 weeks of gestation. The arrows indicate delivery within 48 hours.

Figure 3. Oxylipins associated with delivery before $(n=21)$ and after $(n=59) 34$ weeks of gestation. A non-parametric Mann-Whitney $U$-test was used. Results are shown for oxylipins with $\mathrm{p}$-values $<0.1$. Medians and inter-quartile ranges are noted.

Figure 4. Oxylipins associated with delivery within $(n=14)$ and later than $(n=66) 48$ hours after study inclusion.

All figures are intended for color print. 


\section{SUPPLEMENTARY TABLES}

Table S1. Abbreviation list of the oxylipin compounds analyzed in this study.

\begin{tabular}{|c|c|}
\hline 9,10,13-TriHOME & 9,10,13-trihydroxy-octadecenoic acid \\
\hline 9,12,13-TriHOME & 9,12,13-trihydroxy-octadecenoic acid \\
\hline PGF2a & Prostaglandin F2a \\
\hline Resolvin D1 & 7,8,17-trihydroxy-docosahexaenoic acid \\
\hline Resolvin D2 & 7,16,17-trihydroxy-docosahexaenoic acid \\
\hline TXB2 & Thromboxane B2 \\
\hline LTB4 & Leukotriene B4 \\
\hline PGD2 & Prostaglandin D2 \\
\hline PGE2 & Prostaglandin E2 \\
\hline 9,10-DiHOME & 9,10-dihydroxy-octadecenoic acid \\
\hline 12,13-DiHOME & 12-hydroxy-eicosapentaenoic acid \\
\hline 9,10-DiHODE & 9,10-dihydroxy-octadecadienoic acid \\
\hline 12,13-DiHODE & 12,13-dihydroxy-octadecadienoic acid \\
\hline 15,16-DiHODE & 15,16-dihydroxy-octadecadienoic acid \\
\hline 5,6-DiHETrE & 5,6-dihydroxy-eicosatrienoic acid \\
\hline 8,9-DiHETrE & 8,9-dihydroxy-eicosatrienoic acid \\
\hline 11,12-DiHETrE & 11,12-dihydroxy-eicosatrienoic acid \\
\hline 14,15-DiHETrE & 14,15-dihydroxy-eicosatrienoic acid \\
\hline 8,9-DiHETE & 8,9-dihydroxy-eicosatetraenoic acid \\
\hline 11,12-DiHETE & 11,12-dihydroxy-eicosatetraenoic acid \\
\hline 14,15-DiHETE & 14,15-dihydroxy-eicosatetraenoic acid \\
\hline 17,18-DiHETE & 17,18-dihydroxy-eicosatetraenoic acid \\
\hline 7,8-DiHDPE & 7,8-dihydroxy-docosapentaenoic acid \\
\hline 10,11-DiHDPE & 10,11-dihydroxy-docosapentaenoic acid \\
\hline 13,14-DiHDPE & 13,14-dihydroxy-docosapentaenoic acid \\
\hline 16,17-DiHDPE & 16,17-dihydroxy-docosapentaenoic acid \\
\hline 19,20-DiHDPE & 19,20-dihydroxy-docosapentaenoic acid \\
\hline 9-HODE & 9-hydroxy-octadecadienoic acid \\
\hline 13-HODE & 13-hydroxy-octadecadienoic acid \\
\hline 9-HOTrE & 9S-hydroxy-octadecatrienoic acid \\
\hline 13-HOTrE & 13-hydroxy-octadecatrienoic acid \\
\hline 5-HETE & 5-hydroxy-eicosatetraenoic acid \\
\hline 8-HETE & 8-hydroxy-eicosatetraenoic acid \\
\hline 9-HETE & 9-hydroxy-eicosatetraenoic acid \\
\hline 11-HETE & 11-hydroxy-eicosatetraenoic acid \\
\hline 12-HETE & 12-hydroxy-eicosatetraenoic acid \\
\hline 15-HETE & 15-hydroxy-eicosatetraenoic acid \\
\hline 20-HETE & 20-hydroxy-eicosatetraenoic acid \\
\hline 5-HEPE & 5-hydroxy-eicosapentaenoic acid \\
\hline 12-HEPE & 12,13-dihydroxy-octadecenoic acid \\
\hline 15-HEPE & 15-hydroxy-eicosapentaenoic acid \\
\hline
\end{tabular}


17-HDoHE

15-HETrE

5-OXO-ETE

12-OXO-ETE

15-OXo-ETE

9-Oxo-ODE

13-OXo-ODE

9(10)-EpOME

12(13)-EpOME

EKODE

9(10)-EpODE

12(13)-EpODE

15(16)-EpODE

8(9)-EpETrE

11(12)-EpETrE

14(15)-EpETrE

8(9)-EpETE

11(12)-EpETE

14(15)-EpETE

17(18)-EpETE

7(8)-EpDPE

10(11)-EpDPE

13(14)-EpDPE

16(17)-EpDPE

19(20)-EpDPE 17-hydroxy-docosahexaenoic acid

15-hydroxy-eicosatrienoic acid

5-oxo-eicosatetraenoic acid

12-oxo-eicosatetraenoic acid

15-oxo-eicosatetraenoic acid

9-oxo-10,12-octadecadienoic acid

13-oxo-octadecadienoic acid

9(10)-epoxy-octadecenoic acid

12(13)-epoxy-octadecenoic acid

12(13)-epoxy-9-keto-octadecenoic acid

9(10)-epoxy-octadecadienoic acid

12(13)-epoxy-octadecadienoic acid

15(16)-epoxy-octadecadienoic acid

8(9)-epoxy-eicosatrienoic acid

11(12)-epoxy-eicosatrienoic acid

14(15)-epoxy-eicosatrienoic acid

8(9)-epoxy-eicosatetraenoic acid

11(12)-epoxy-eicosatetraenoic acid

14(15)-epoxy-eicosatetraenoic acid

17(18)-epoxy-eicosatetraenoic acid

7(8)-epoxy docosapentaenoic acid

10(11)-epoxy docosapentaenoic acid

13(14)-epoxy docosapentaenoic acid

16(17)-epoxy docosapentaenoic acid

19(20)-epoxy docosapentaenoic acid 
Table S2. Median values (pmol/mL) and quartiles (Q1-Q3) for all oxylipins in the study population of women with preterm labor grouped for delivery before or after 34 weeks and delivery within or after 48 hours, respectively. Values below limit of detection (LOD) were substituted with LOD $/ \sqrt{2}$. The Mann-Whitney $U$-test was used for non-parametric analyses. P-values $<0.1$ are marked in bold. DF, detection frequency (percentage of samples above LOD).

\begin{tabular}{|c|c|c|c|c|c|c|c|}
\hline \multirow[b]{2}{*}{ Variable } & \multirow[b]{2}{*}{ DF (\%) } & \multicolumn{3}{|c|}{ Delivery before or after 34 weeks } & \multicolumn{3}{|c|}{ Delivery within or after $\mathbf{4 8}$ hours } \\
\hline & & $<34$ weeks & $\geq 34$ weeks & $\mathbf{p}$ & $<48 \mathrm{~h}$ & $\geq 48 \mathrm{~h}$ & $\mathbf{p}$ \\
\hline $\mathbf{N}$ & & 21 & 59 & & 14 & 66 & \\
\hline 9,10,13-TriHOME & 10 & $0.06(0.06-0.06)$ & $0.06(0.06-0.06)$ & 0.397 & $0.06(0.06-0.06)$ & $0.06(0.06-0.06)$ & 0.807 \\
\hline 9,12,13-TriHOME & 61 & $0.76(0.02-2.49)$ & $1.16(0.02-4.05)$ & 0.434 & $0.02(0.02-1.09)$ & $1.19(0.02-4.05)$ & 0.056 \\
\hline PGF2a & 6 & $0.05(0.05-0.05)$ & $0.05(0.05-0.05)$ & 0.761 & $0.05(0.05-0.05)$ & $0.05(0.05-0.05)$ & 0.945 \\
\hline Resolvin D1 & 0 & $0.02(0.02-0.02)$ & $0.02(0.02-0.02)$ & & $0.02(0.02-0.02)$ & $0.02(0.02-0.02)$ & \\
\hline Resolvin D2 & 0 & $1.01(1.01-1.01)$ & $1.01(1.01-1.01)$ & & $1.01(1.01-1.01)$ & $1.01(1.01-1.01)$ & \\
\hline TXB2 & 53 & $0.12(0.02-0.99)$ & $0.12(0.02-0.34)$ & 0.610 & $0.12(0.02-1.03)$ & $0.12(0.02-0.34)$ & 0.411 \\
\hline LTB4 & 0 & $0.02(0.02-0.02)$ & $0.02(0.02-0.02)$ & & $0.02(0.02-0.02)$ & $0.02(0.02-0.02)$ & \\
\hline PGD2 & 5 & $0.05(0.05-0.05)$ & $0.05(0.05-0.05)$ & 0.680 & $0.05(0.05-0.05)$ & $0.05(0.05-0.05)$ & 0.876 \\
\hline PGE2 & 0 & $0.05(0.05-0.05)$ & $0.05(0.05-0.05)$ & & $0.05(0.05-0.05)$ & $0.05(0.05-0.05)$ & \\
\hline 9,10-DiHOME & 100 & $2.53(1.44-3.12)$ & $3.81(1.85-5.46)$ & 0.090 & $2.50(1.35-3.12)$ & $3.22(1.85-5.24)$ & 0.075 \\
\hline 12,13-DiHOME & 100 & $4.23(2.77-7.25)$ & $6.04(3.34-10.61)$ & 0.138 & $3.96(2.52-7.25)$ & $6.03(3.95-10.26)$ & 0.113 \\
\hline 9,10-DiHODE & 98 & $0.17(0.13-0.25)$ & $0.32(0.16-0.48)$ & 0.021 & $0.16(0.12-0.25)$ & $0.29(0.17-0.45)$ & 0.020 \\
\hline 12,13-DiHODE & 31 & $0.02(0.02-0.02)$ & $0.02(0.02-0.68)$ & 0.101 & $0.02(0.02-0.02)$ & $0.02(0.02-0.67)$ & 0.433 \\
\hline 15,16-DiHODE & 100 & $40.9(23.1-57.1)$ & $51.7(37.8-95.6)$ & 0.104 & $33.9(23.1-61.1)$ & $51.6(33.4-85.0)$ & 0.192 \\
\hline 5,6-DiHETrE & 16 & $0.06(0.06-0.73)$ & $0.06(0.06-0.06)$ & 0.138 & $0.06(0.06-0.06)$ & $0.06(0.06-0.06)$ & 0.778 \\
\hline 8,9-DiHETrE & 14 & $0.02(0.02-0.02)$ & $0.02(0.02-0.02)$ & 0.664 & $0.02(0.02-0.02)$ & $0.02(0.02-0.02)$ & 0.647 \\
\hline 11,12-DiHETrE & 94 & $0.64(0.54-0.85)$ & $0.55(0.47-0.69)$ & 0.082 & $0.62(0.53-0.82)$ & $0.56(0.47-0.70)$ & 0.260 \\
\hline 14,15-DiHETrE & 93 & $0.58(0.45-0.73)$ & $0.51(0.44-0.58)$ & 0.355 & $0.54(0.44-0.70)$ & $0.51(0.45-0.61)$ & 0.925 \\
\hline 8,9-DiHETE & 0 & $0.02(0.02-0.02)$ & $0.02(0.02-0.02)$ & & $0.02(0.02-0.02)$ & $0.02(0.02-0.02)$ & \\
\hline 11,12-DiHETE & 4 & $0.00(0.00-0.00)$ & $0.00(0.00-0.00)$ & 0.931 & $0.00(0.00-0.00)$ & $0.00(0.00-0.00)$ & 0.817 \\
\hline
\end{tabular}




\begin{tabular}{|c|c|c|c|c|c|c|c|}
\hline 14,15-DiHETE & 0 & $0.00(0.00-0.00)$ & $0.00(0.00-0.00)$ & & $0.00(0.00-0.00)$ & $0.00(0.00-0.00)$ & \\
\hline 17,18-DiHETE & 100 & $0.38(0.30-0.48)$ & $0.34(0.28-0.43)$ & 0.361 & $0.38(0.32-0.58)$ & $0.34(0.28-0.43)$ & 0.234 \\
\hline 7,8-DiHDPE & 15 & $0.05(0.05-0.05)$ & $0.05(0.05-0.05)$ & 0.712 & $0.05(0.05-0.05)$ & $0.05(0.05-0.05)$ & 0.603 \\
\hline 10,11-DiHDPE & 20 & $0.02(0.02-0.02)$ & $0.02(0.02-0.02)$ & 0.680 & $0.02(0.02-0.02)$ & $0.02(0.02-0.02)$ & 0.769 \\
\hline 13,14-DiHDPE & 9 & $0.02(0.02-0.02)$ & $0.02(0.02-0.02)$ & 0.948 & $0.02(0.02-0.02)$ & $0.02(0.02-0.02)$ & 0.915 \\
\hline 16,17-DiHDPE & 0 & $0.02(0.02-0.02)$ & $0.02(0.02-0.02)$ & & $0.02(0.02-0.02)$ & $0.02(0.02-0.02)$ & \\
\hline 19,20-DiHDPE & 15 & $0.02(0.02-0.02)$ & $0.02(0.02-0.02)$ & 0.602 & $0.02(0.02-0.02)$ & $0.02(0.02-0.02)$ & 0.577 \\
\hline 9-HODE & 100 & $12.0(9.3-19.7)$ & $13.5(8.9-23.2)$ & 0.712 & $10.5(8.6-15.3)$ & $13.5(9.7-23.2)$ & 0.312 \\
\hline 13-HODE & 63 & $4.33(0.00-8.16)$ & $1.61(0.00-9.15)$ & 0.440 & $1.61(0.00-8.16)$ & $1.61(0.00-9.15)$ & 0.836 \\
\hline 9-HOTrE & 65 & $0.40(0.00-1.00)$ & $0.84(0.00-1.72)$ & 0.095 & $0.20(0.00-1.00)$ & $0.76(0.00-1.60)$ & 0.152 \\
\hline 13-HOTrE & 26 & $0.02(0.02-0.02)$ & $0.02(0.02-2.53)$ & 0.253 & $0.02(0.02-0.02)$ & $0.02(0.02-2.43)$ & 0.376 \\
\hline 5-HETE & 0 & $0.02(0.02-0.02)$ & $0.02(0.02-0.02)$ & & $0.02(0.02-0.02)$ & $0.02(0.02-0.02)$ & \\
\hline 8-HETE & 49 & $0.17(0.02-0.25)$ & $0.02(0.02-0.18)$ & 0.020 & $0.18(0.09-0.25)$ & $0.02(0.02-0.19)$ & 0.050 \\
\hline 9-HETE & 0 & $0.02(0.02-0.02)$ & $0.02(0.02-0.02)$ & & $0.02(0.02-0.02)$ & $0.02(0.02-0.02)$ & \\
\hline 11-HETE & 100 & $0.30(0.15-0.49)$ & $0.20(0.14-0.30)$ & 0.135 & $0.27(0.15-0.44)$ & $0.21(0.14-0.32)$ & 0.356 \\
\hline 12-HETE & 28 & $0.02(0.02-0.38)$ & $0.02(0.02-0.02)$ & 0.355 & $0.02(0.02-5.29)$ & $0.02(0.02-0.02)$ & 0.318 \\
\hline 15-HETE & 9 & $0.02(0.02-0.02)$ & $0.02(0.02-0.02)$ & 0.595 & $0.02(0.02-0.02)$ & $0.02(0.02-0.02)$ & 0.684 \\
\hline 20-HETE & 24 & $0.02(0.02-0.49)$ & $0.02(0.02-0.02)$ & 0.141 & $0.02(0.02-0.49)$ & $0.02(0.02-0.02)$ & 0.171 \\
\hline 5-HEPE & 10 & $0.06(0.06-0.06)$ & $0.06(0.06-0.06)$ & 0.385 & $0.06(0.06-0.06)$ & $0.06(0.06-0.06)$ & 0.788 \\
\hline 12-HEPE & 46 & $0.02(0.02-0.75)$ & $0.02(0.02-0.38)$ & 0.648 & $0.09(0.02-0.88)$ & $0.02(0.02-0.41)$ & 0.749 \\
\hline 15-HEPE & 0 & $0.06(0.06-0.06)$ & $0.06(0.06-0.06)$ & & $0.06(0.06-0.06)$ & $0.06(0.06-0.06)$ & \\
\hline 17-HDoHE & 9 & $0.06(0.06-0.06)$ & $0.06(0.06-0.06)$ & 0.572 & $0.06(0.06-0.06)$ & $0.06(0.06-0.06)$ & 0.935 \\
\hline 15-HETrE & 3 & $0.02(0.02-0.02)$ & $0.02(0.02-0.02)$ & 0.837 & $0.02(0.02-0.02)$ & $0.02(0.02-0.02)$ & 0.866 \\
\hline 5-Oxo-ETE & 0 & $0.06(0.06-0.06)$ & $0.06(0.06-0.06)$ & & $0.06(0.06-0.06)$ & $0.06(0.06-0.06)$ & \\
\hline 12-oxo-ETE & 0 & $0.12(0.12-0.12)$ & $0.12(0.12-0.12)$ & & $0.12(0.12-0.12)$ & $0.12(0.12-0.12)$ & \\
\hline 15-oxo-ETE & 16 & $0.02(0.02-0.02)$ & $0.02(0.02-0.02)$ & 0.871 & $0.02(0.02-0.02)$ & $0.02(0.02-0.02)$ & 0.494 \\
\hline 9-oxo-ODE & 0 & $2.59(2.59-2.59)$ & $2.59(2.59-2.59)$ & & $2.59(2.59-2.59)$ & $2.59(2.59-2.59)$ & \\
\hline 13-Oxo-ODE & 9 & $0.13(0.13-0.13)$ & $0.13(0.13-0.13)$ & 0.905 & $0.13(0.13-0.13)$ & $0.13(0.13-0.13)$ & 0.945 \\
\hline 9(10)-ЕрОМЕ & 100 & $0.76(0.51-1.43)$ & $0.84(0.62-1.19)$ & 0.983 & $0.76(0.51-1.34)$ & $0.84(0.62-1.20)$ & 0.621 \\
\hline 12(13)-ЕpOME & 100 & $3.14(2.09-5.00)$ & $2.98(1.99-5.32)$ & 0.939 & $2.71(2.09-3.95)$ & $3.11(1.99-5.32)$ & 0.404 \\
\hline
\end{tabular}




\begin{tabular}{|c|c|c|c|c|c|c|c|}
\hline EKODE & 100 & 7.88 (3.99-11.47) & $6.31(4.34-11.51)$ & 0.974 & $5.84(3.99-12.57)$ & 6.53 (4.34-11.47) & 0.836 \\
\hline 9(10)-EpODE & 9 & $0.00(0.00-0.00)$ & $0.00(0.00-0.00)$ & 0.618 & $0.00(0.00-0.00)$ & $0.00(0.00-0.00)$ & 0.712 \\
\hline 12(13)-EpODE & 0 & $0.02(0.02-0.02)$ & $0.02(0.02-0.02)$ & & $0.02(0.02-0.02)$ & $0.02(0.02-0.02)$ & \\
\hline 15(16)-EpODE & 0 & $0.02(0.02-0.02)$ & $0.02(0.02-0.02)$ & & $0.02(0.02-0.02)$ & $0.02(0.02-0.02)$ & \\
\hline 5(6)-EpETrE & 0 & $0.06(0.06-0.06)$ & $0.06(0.06-0.06)$ & & $0.06(0.06-0.06)$ & $0.06(0.06-0.06)$ & \\
\hline 8(9)-EpETrE & 0 & $0.06(0.06-0.06)$ & $0.06(0.06-0.06)$ & & $0.06(0.06-0.06)$ & $0.06(0.06-0.06)$ & \\
\hline 11(12)-EpETrE & 0 & $0.02(0.02-0.02)$ & $0.02(0.02-0.02)$ & & $0.02(0.02-0.02)$ & $0.02(0.02-0.02)$ & \\
\hline 14(15)-EpETrE & 0 & $0.06(0.06-0.06)$ & $0.06(0.06-0.06)$ & & $0.06(0.06-0.06)$ & $0.06(0.06-0.06)$ & \\
\hline 8(9)-ЕpETE & 0 & $0.12(0.12-0.12)$ & $0.12(0.12-0.12)$ & & $0.12(0.12-0.12)$ & $0.12(0.12-0.12)$ & \\
\hline 11(12)-EpETE & 0 & $0.02(0.02-0.02)$ & $0.02(0.02-0.02)$ & & $0.02(0.02-0.02)$ & $0.02(0.02-0.02)$ & \\
\hline 14(15)-EpETE & 0 & $0.02(0.02-0.02)$ & $0.02(0.02-0.02)$ & & $0.02(0.02-0.02)$ & $0.02(0.02-0.02)$ & \\
\hline 17(18)-EpETE & 0 & $0.00(0.00-0.00)$ & $0.00(0.00-0.00)$ & & $0.00(0.00-0.00)$ & $0.00(0.00-0.00)$ & \\
\hline 7(8)-EpDPE & 0 & $0.02(0.02-0.02)$ & $0.02(0.02-0.02)$ & & $0.02(0.02-0.02)$ & $0.02(0.02-0.02)$ & \\
\hline 10(11)-EpDPE & 0 & $0.02(0.02-0.02)$ & $0.02(0.02-0.02)$ & & $0.02(0.02-0.02)$ & $0.02(0.02-0.02)$ & \\
\hline 13(14)-EpDPE & 0 & $0.02(0.02-0.02)$ & $0.02(0.02-0.02)$ & & $0.02(0.02-0.02)$ & $0.02(0.02-0.02)$ & \\
\hline 16(17)-EpDPE & 0 & $0.11(0.11-0.11)$ & $0.11(0.11-0.11)$ & & $0.11(0.11-0.11)$ & $0.11(0.11-0.11)$ & \\
\hline 19(20)-EpDPE & 0 & $0.02(0.02-0.02)$ & $0.02(0.02-0.02)$ & & $0.02(0.02-0.02)$ & $0.02(0.02-0.02)$ & \\
\hline
\end{tabular}


Table S3. Oxylipins ( $\mathrm{pmol} / \mathrm{mL}$ ) associated with delivery before 34 weeks of gestation

following preterm labor analyzed using logistic regression. In the multivariate model the variables were adjusted for pneumatic tube transport. All quartiles shown.

\begin{tabular}{|c|c|c|c|c|c|c|c|}
\hline \multirow[b]{2}{*}{ Variable } & \multirow[b]{2}{*}{ Total } & \multicolumn{2}{|c|}{$\begin{array}{c}\text { Delivery } \\
<\text { week } 34\end{array}$} & \multicolumn{2}{|c|}{$\begin{array}{l}\text { Univariate logistic } \\
\text { regression }\end{array}$} & \multicolumn{2}{|c|}{$\begin{array}{l}\text { Multivariate logistic } \\
\text { regression }\end{array}$} \\
\hline & & $n$ & $\%$ & OR (95\% Cl) & $p$ & OR (95\% Cl) & $p$ \\
\hline \multicolumn{8}{|c|}{ Pneumatic tube transport } \\
\hline No & 15 & 7 & 47 & 1.00 & & 1.00 & \\
\hline Yes & 65 & 14 & 22 & $0.31(0.10-1.03)$ & 0.053 & $0.38(0.11-1.38)$ & 0.137 \\
\hline
\end{tabular}

\section{9,10-DiHOME Quartiles}

$\begin{array}{llllcl}\leq 1.701 & 20 & 7 & 35 & 1.00 & \\ 1.701-2.858 & 20 & 7 & 35 & 0.63(0.39-1.02) & \\ 2.859-4.872 & 20 & 5 & 25 & 0.40(0.15-1.05) & \\ >4.872 & 20 & 2 & 10 & 0.25(0.06-1.08) & 0.062\end{array}$

\section{9,10-DiHODE Quartiles}

\begin{tabular}{|c|c|c|c|c|c|c|c|}
\hline$\leq 0.142$ & 21 & 7 & 33 & 1.00 & & 1.00 & \\
\hline $0.142-0.236$ & 19 & 9 & 47 & $0.58(0.35-0.94)$ & & $0.53(0.32-0.90)$ & \\
\hline $0.237-0.441$ & 20 & 3 & 15 & $0.33(0.13-0.89)$ & & $0.28(0.10-0.81)$ & \\
\hline$>0.441$ & 20 & 2 & 10 & $0.19(0.04-0.84)$ & 0.028 & $0.15(0.03-0.73)$ & 0.017 \\
\hline
\end{tabular}

\section{9-HOTrE Quartiles}

$\begin{array}{lccccc}\leq 702(\mathrm{Q} 1+\mathrm{Q} 2) & 40 & 14 & 35 & 1.00 & \\ 0.703-1.521 & 20 & 5 & 25 & 0.49(0.24-1.00) & \\ >1.521 & 20 & 2 & 10 & 0.24(0.06-1.00) & 0.050\end{array}$

\section{8-HETE Quartiles}

$\begin{array}{llllcl}\leq 0.020(\mathrm{Q} 1+\mathrm{Q} 2) & 41 & 6 & 15 & 1.00 & \\ 0.020-0.194 & 19 & 8 & 42 & 1.81(0.99-3.32) & \\ >0.194 & 20 & 7 & 35 & 3.28(0.97-11.05) & 0.055\end{array}$

\section{1,12-DiHETrE}

\section{Quartiles}

\begin{tabular}{|c|c|c|c|c|c|c|c|}
\hline$\leq 0.486$ & 20 & 3 & 15 & 1.00 & & 1.00 & \\
\hline $0.486-0.563$ & 20 & 5 & 25 & $1.58(0.98-2.55)$ & & $1.66(0.99-2.78)$ & \\
\hline $0.564-0.739$ & 20 & 4 & 20 & $2.49(0.95-6.52)$ & & $2.75(0.98-7.71)$ & \\
\hline$>0.739$ & 20 & 9 & 45 & $3.94(0.93-16.65)$ & 0.062 & $4.57(0.98-21.40)$ & 0.050 \\
\hline
\end{tabular}


Table S4. Oxylipins (pmol/mL) associated with delivery within 48 hours after admission to hospital due to preterm labor analyzed using logistic regression. In the multivariate model the variables were adjusted for pneumatic tube transport. All quartiles shown.

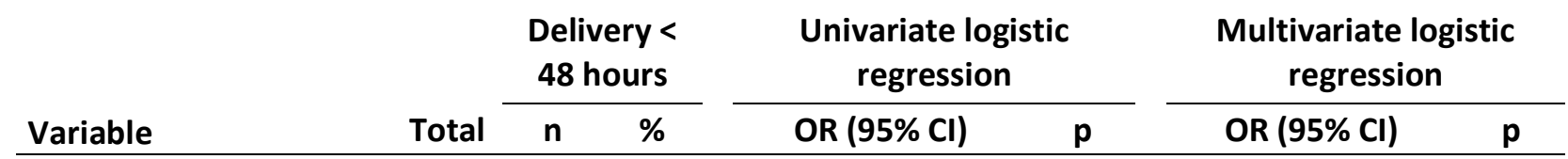

Pneumatic tube transport

$\begin{array}{lccccccc}\text { No } & 15 & 4 & 27 & 1.00 & & 1.00 & \\ \text { Yes } & 65 & 10 & 15 & 0.50(0.13-1.93) & 0.306 & 0.54(0.13-2.18) & 0.377\end{array}$

9,12,13-TriHOME Quartiles

$\begin{array}{llcccc}\leq 1.017(\mathrm{Q} 1+\mathrm{Q} 2) & 40 & 9 & 23 & 1.00 & \\ 1.018-3.332 & 20 & 4 & 20 & 0.52(0.23-1.20) & \\ >3.332 & 20 & 1 & 5 & 0.27(0.05-1.45) & 0.121\end{array}$

9,10-DiHOME Quartiles

$\begin{array}{lllccc}\leq 1.701 & 20 & 6 & 30 & 1.00 & \\ 1.701-2.858 & 20 & 4 & 20 & 0.55(0.31-0.99) & \\ 2.859-4.872 & 20 & 3 & 15 & 0.30(0.09-0.98) & \\ >4.872 & 20 & 1 & 5 & 0.17(0.03-0.97) & 0.042\end{array}$

9,10-DiHODE Quartiles

\begin{tabular}{|c|c|c|c|c|c|c|}
\hline$\leq 0.142$ & 21 & 6 & 29 & 1.00 & & 1.00 \\
\hline $0.142-0.236$ & 19 & 5 & 26 & $0.52(0.29-0.94)$ & & $0.52(0.29-0.95)$ \\
\hline $0.237-0.441$ & 20 & 2 & 10 & $0.27(0.08-0.88)$ & & $0.27(0.08-0.91)$ \\
\hline$>0.441$ & 20 & 1 & 5 & $0.14(0.02-0.83)$ & 0.028 & $0.14(0.02-0.87)$ \\
\hline
\end{tabular}

8_HETE Quartiles

$\begin{array}{lllll}\leq 0.020(\mathrm{Q} 1+\mathrm{Q} 2) & 41 & 3 & 7 & 1.00\end{array}$

$\begin{array}{lllll}0.020-0.194 & 19 & 7 & 37 & 1.75(0.88-3.51)\end{array}$

$\begin{array}{llllll}>0.194 & 20 & 4 & 20 & 3.08(0.77-12.29) & 0.106\end{array}$ 



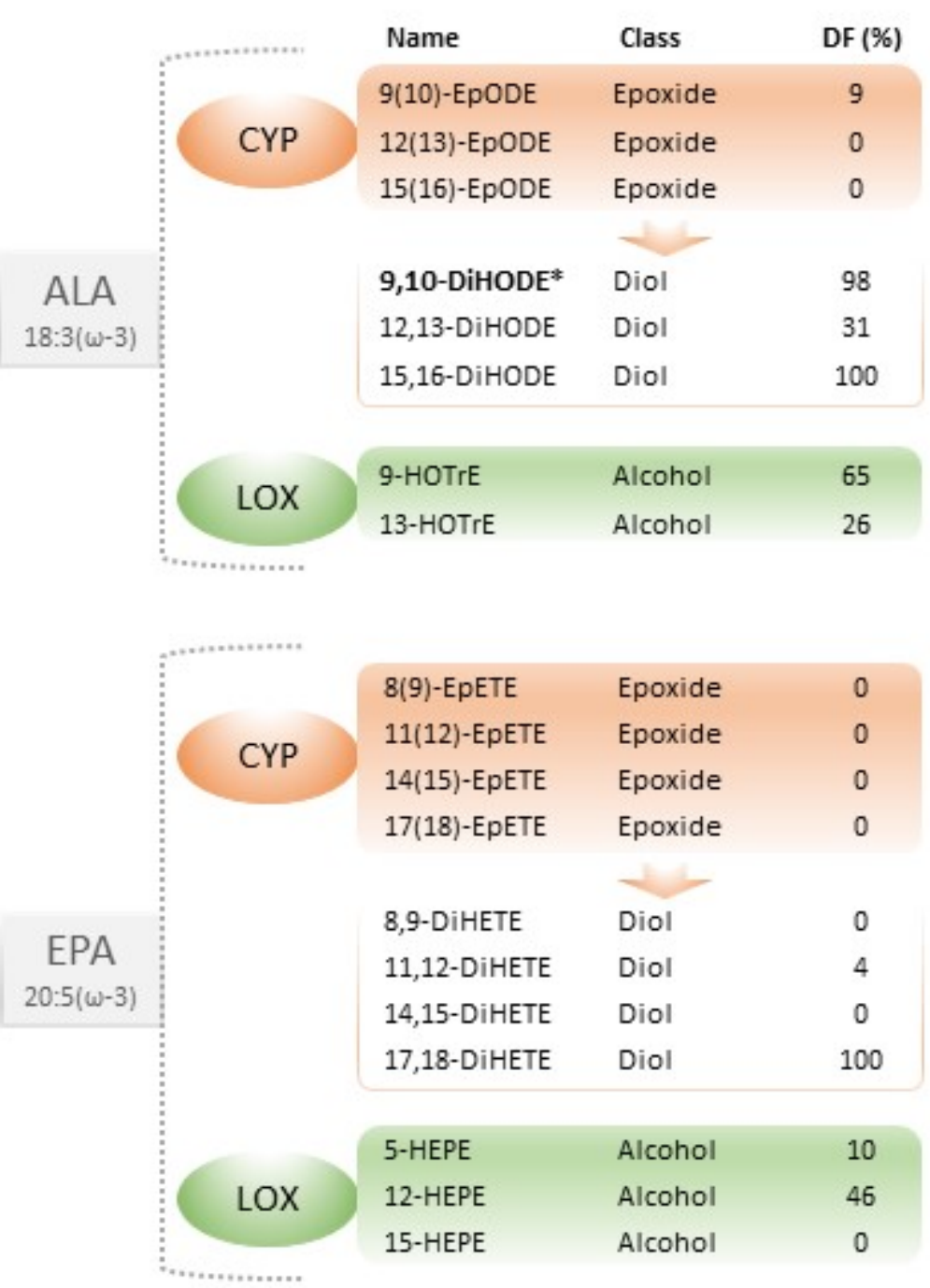

${ }^{*}$ Lower levels associated with delivery before 34 weeks and within 48 hours **Higher levels associated with delivery before 34 weeks

***Higher levels associated with delivery within 48 hours

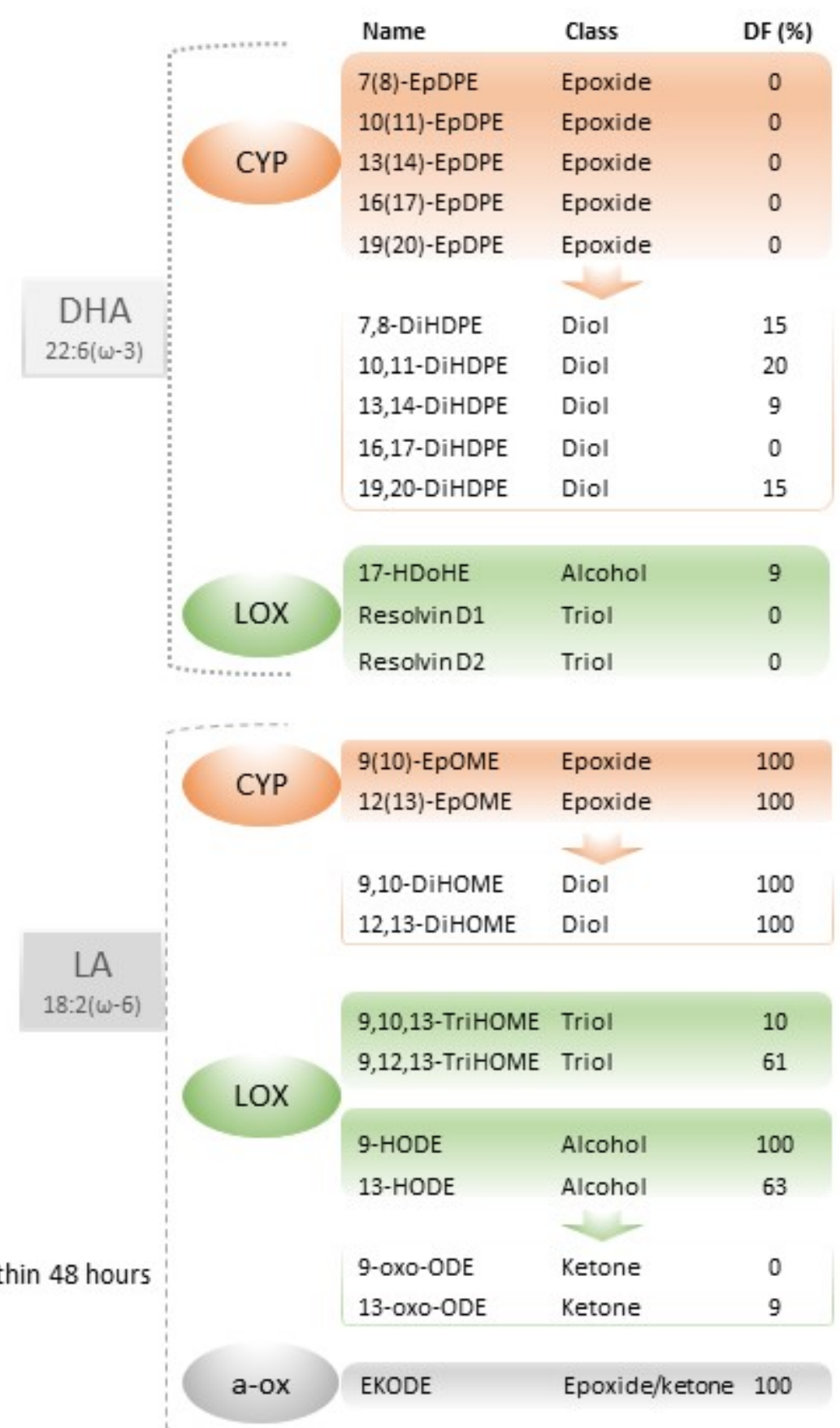

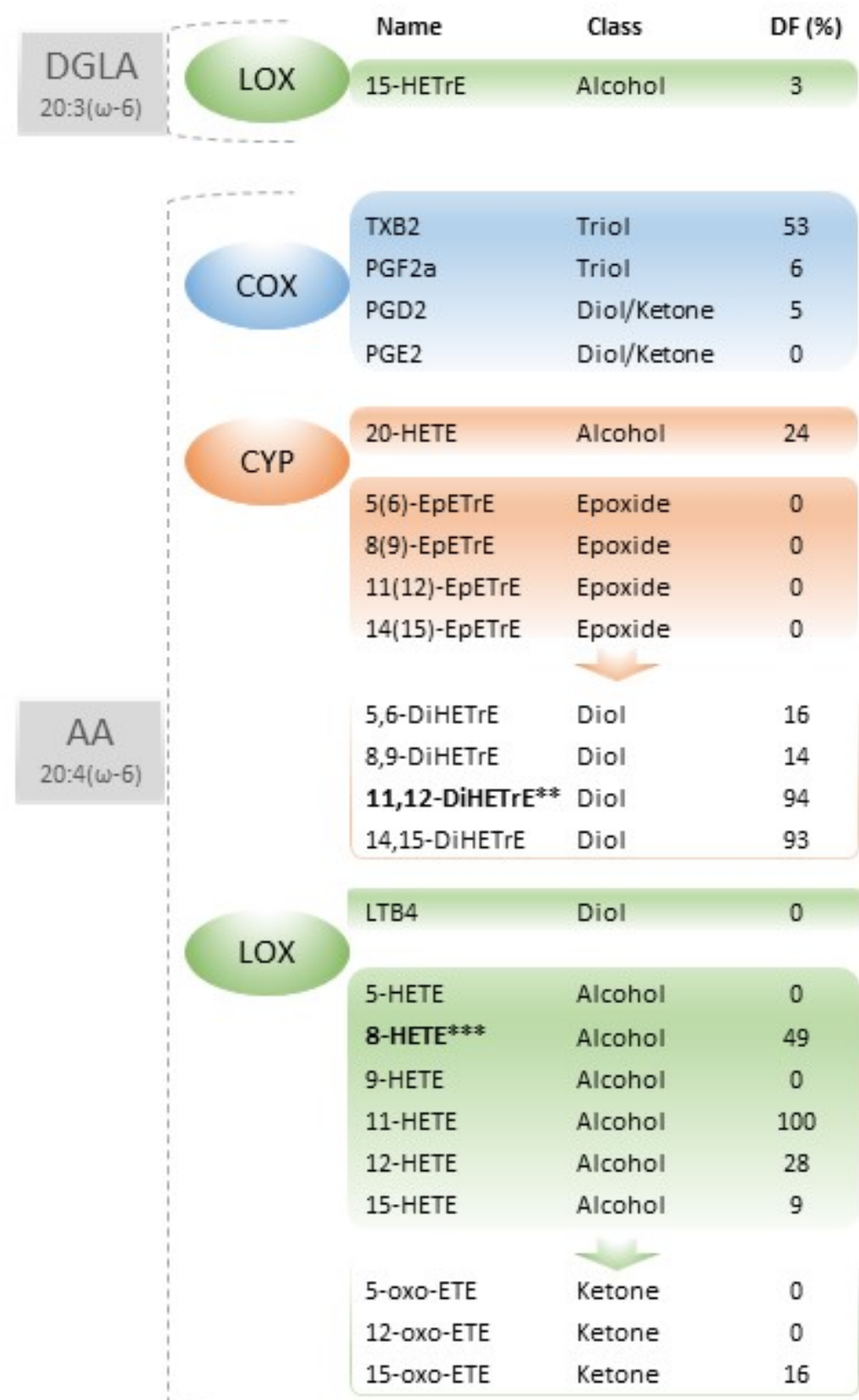


A

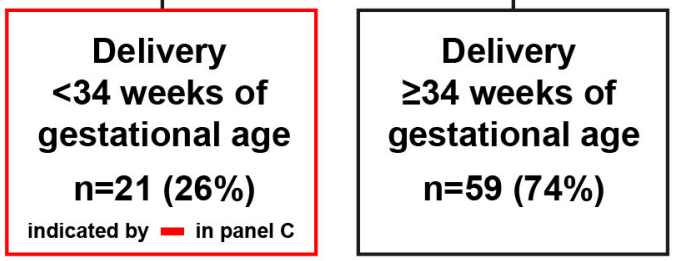

B

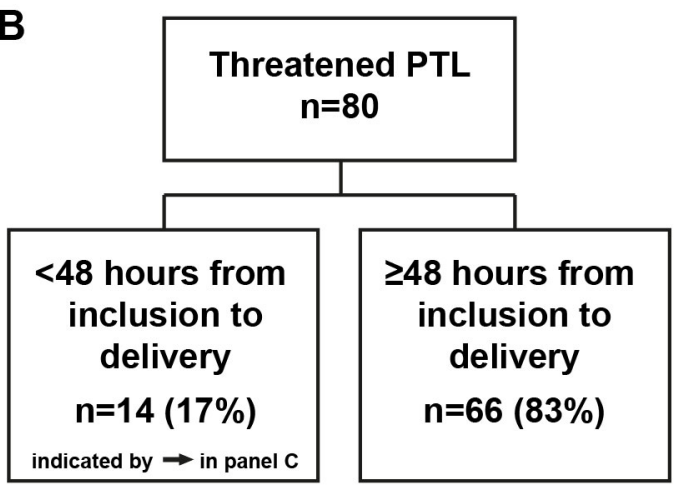

C Time line: inclusion until delivery

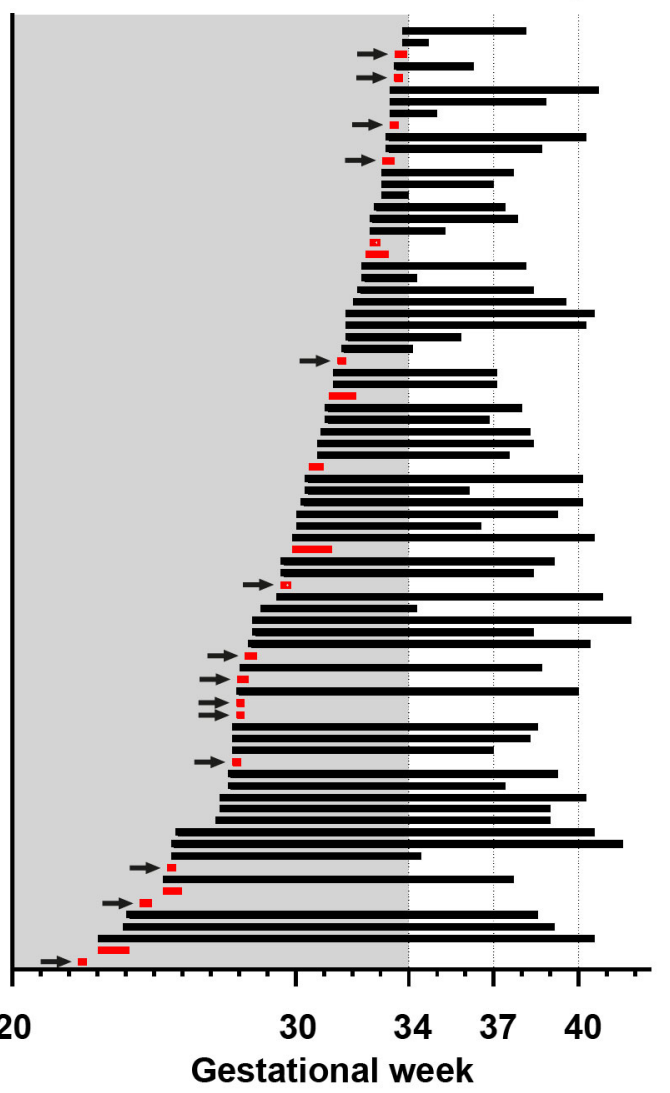




\section{8-HETE}

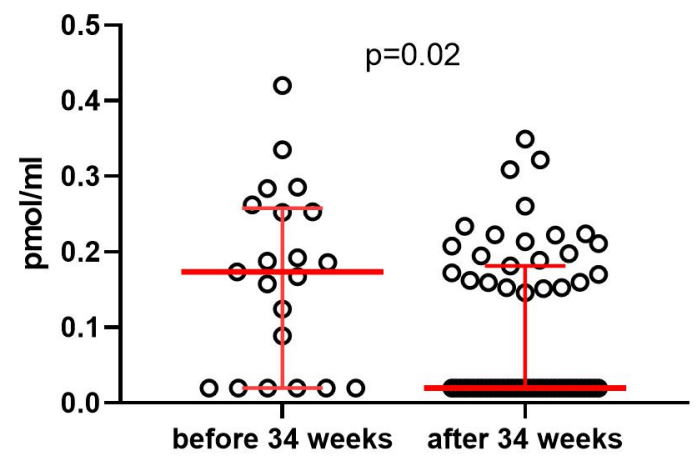

\section{9,10-DiHODE}

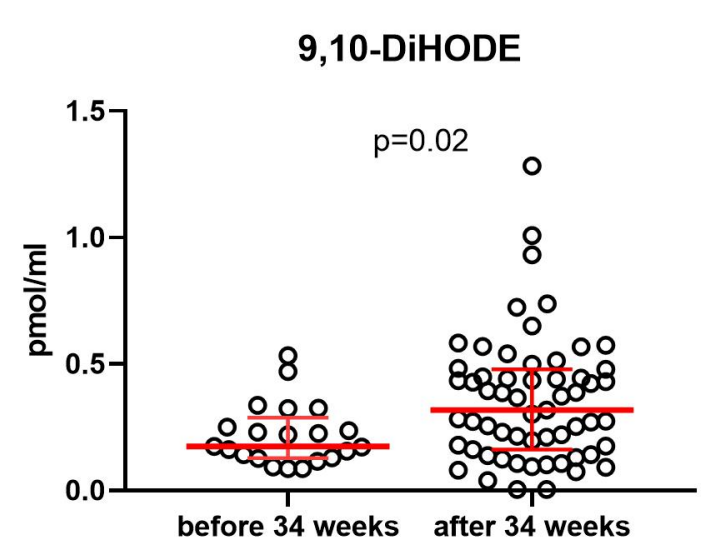

9-HOTrE

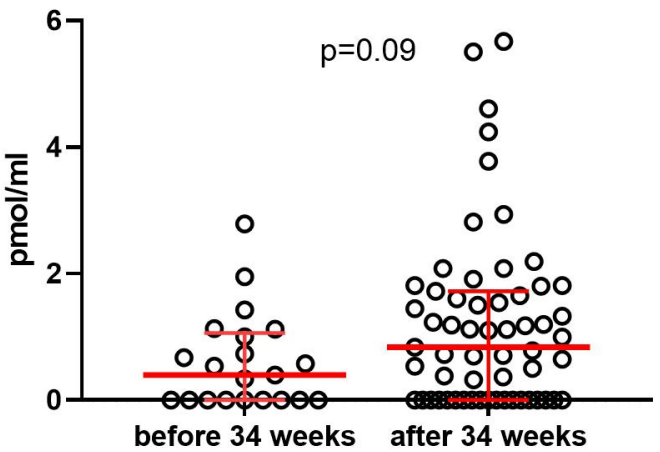

11,12-DiHETrE

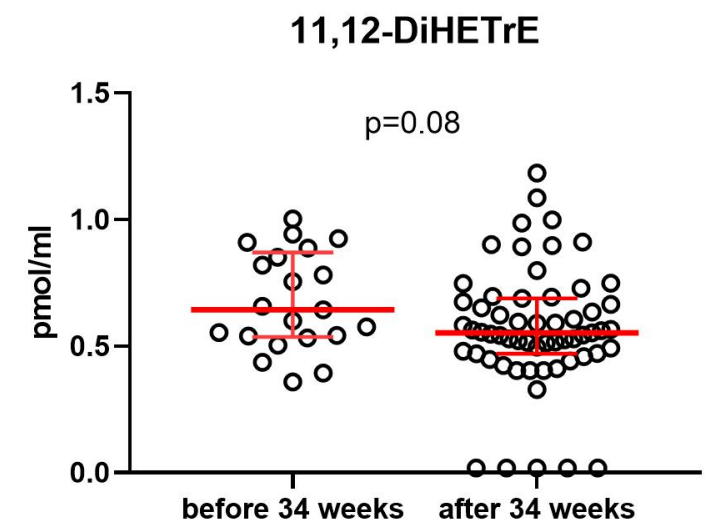

\section{9,10-DiHOME}

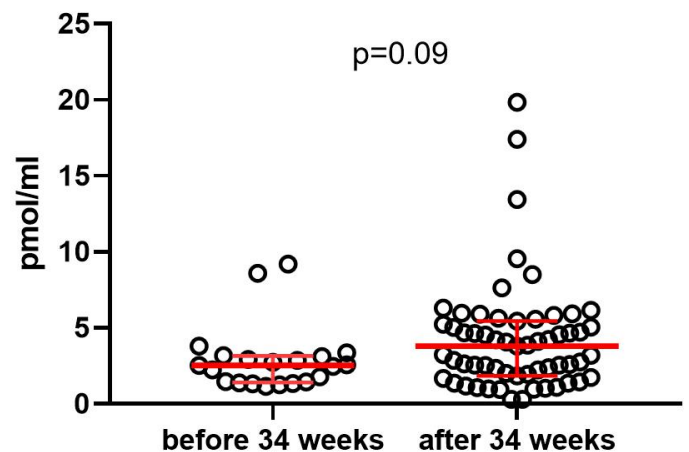


8-HETE

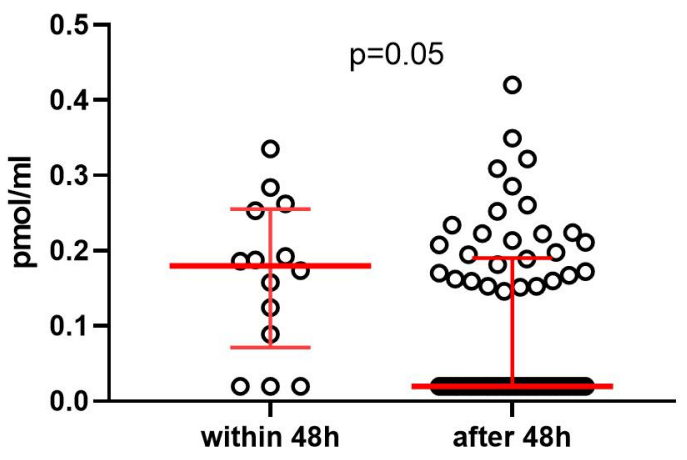

9,10-DiHOME

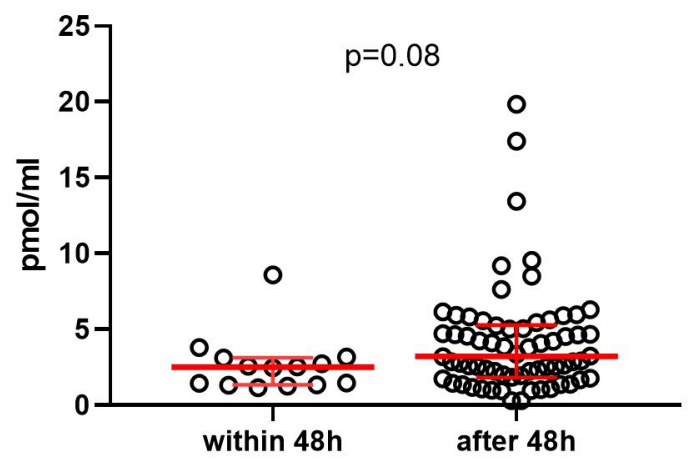

9,12,13-TriHOME

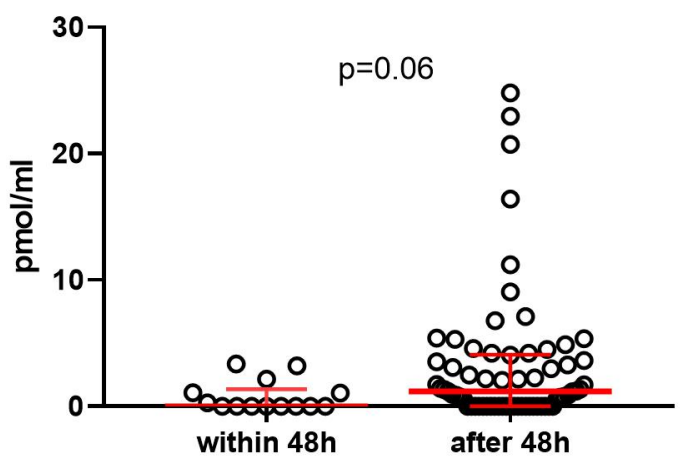

9,10-DiHODE

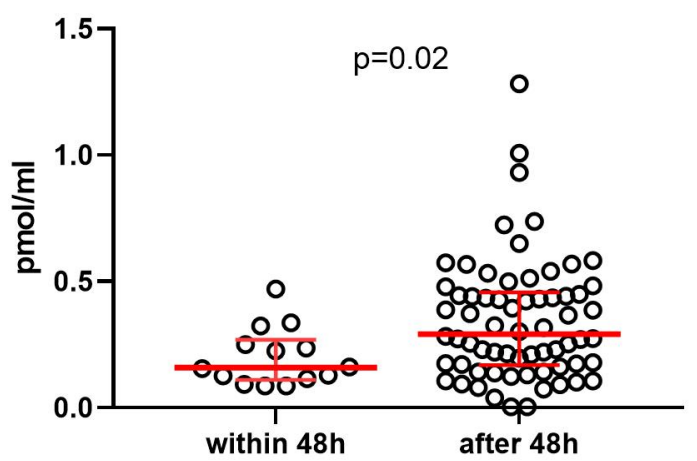

